\title{
Vulnerable Atherosclerotic Plaque: From the Basic Research Laboratory to the Clinic
}

\author{
Konstantinos Toutouzas Konstantinos Stathogiannis Andreas Synetos \\ Antonios Karanasos Christodoulos Stefanadis
}

First Department of Cardiology, Hippokration Hospital, Athens Medical School, Athens, Greece

\section{Key Words}

Vulnerable plaque $\cdot$ Thin-cap fibroatheroma $\cdot$ Intravascular imaging $\cdot$ Intravascular ultrasound $\cdot$ Optical coherence tomography $\cdot$ Intravascular thermography

\begin{abstract}
Coronary heart disease is the commonest cause of death in Western countries, and atherosclerotic plaques that are prone to rupture have been implicated in the pathogenesis of acute coronary syndromes (ACS). Intensive research has been directed at plaque detection, and various invasive methods have been developed thus far that fulfill this purpose and a lot of them are being applied in the clinical setting. Since invasive methods cannot be used for primary prevention, non-invasive imaging modalities are being studied to enhance the diagnostic armory of clinicians in their difficult task of detecting and preventing ACS.
\end{abstract}

Copyright $\odot 2012$ S. Karger AG, Basel
(C) 2012 S. Karger AG, Basel

$0008-6312 / 12 / 1234-0248 \$ 38.00 / 0$

Fax +41613061234

E-Mail karger@karger.ch

www.karger.com
Accessible online at: www.karger.com/crd

\section{Introduction}

Coronary heart disease remains the single most common cause of death in the European Union and the USA, even though there has been a reduction in the crude number of coronary heart disease deaths when compared with the previous decade $[1,2]$. Atherosclerosis is usually complicated by acute thrombosis, which is triggered by the rupture or erosion of an atherosclerotic plaque, which in turn leads to acute ischemic events. The Framingham risk equation [3] and the Systematic Coronary Risk Evaluation system [4] are currently being used to identify high-risk patients and predict the risk of a future acute coronary syndrome (ACS). However, these scores accurately estimate the cardiovascular risk of middle-aged men but tend to significantly underestimate that of younger patients $[5,6]$. The rupture of an unstable coronary atherosclerotic plaque usually precedes a majority of acute cardiovascular events [7]. Since most acute events are caused by the rupture or erosion of nonhemodynamically significant plaques rather than the progression of flow-limiting lesions [8], indicating that the predictive value of noninvasive stress testing for predicting acute vascular events is particularly poor, the need to develop new diagnostic tools that focus on de-

Konstantinos Toutouzas, MD

Athens Medical School

26 Karaoli and Dimitriou str.

GR-15562 Holargos, Athens (Greece)

E-Mail ktoutouz@gmail.com 
tecting rupture-prone plaques is emerging. The purpose of this review is to focus mainly on the intravascular modalities that are being used and to briefly assess the existing noninvasive imaging modalities used for coronary plaque detection.

\section{Vulnerable Plaque Concept}

During the past decade, identification of plaques likely to cause an acute event in the future has been a topic of intensive research. The term vulnerable plaque denotes a plaque that is more prone to lead to ACS. Although such events could be triggered by plaque rupture, plaque erosion or plaque disruption due to calcified nodules, the pathophysiology of the latter mechanisms is currently poorly understood $[9,10]$. Thus, most attempts to identify vulnerable plaques have focused on the identification of rupture-prone plaques. Histological characteristics of such plaques include the presence of a thin fibrous cap $(<65 \mu \mathrm{m})$, large necrotic core, expansive remodeling, increased neovascularization and infiltration of the fibrous cap by activated macrophages [11]. The type of plaque that is associated with these features is called a thin-cap fibroatheroma and is considered the precursor of a ruptured plaque.

\section{Invasive Imaging Modalities}

There are various intravascular imaging modalities that have been used in an attempt to identify vulnerable atheromatic plaques, in animal and human studies, each of them having its own advantages and drawbacks.

\section{Intravascular Ultrasound}

Grayscale intravascular ultrasound (IVUS), being the first invasive method used for imaging of the vascular wall, has been applied for vulnerable plaque characterization. It can assess plaque burden and the presence of expansive remodeling, which constitute two important features of plaque vulnerability, and it can classify atheromatic plaques as soft, fibrous, calcific or mixed, without, however, being able to assess the actual histologic composition [12]. However, the limited resolution does not allow for accurate tissue characterization or for identification of the most crucial components of vulnerable plaque, i.e. necrotic core content and fibrous cap thickness. These limitations have led to the development of signal processing methods such as virtual histology IVUS

Vulnerable Atherosclerotic Plaque
(VH-IVUS) and integrated backscatter IVUS (IB-IVUS) that use signal processing methodologies in order to assess the tissue composition of the plaque.

\section{Virtual Histology IVUS}

VH-IVUS uses a mathematical autoregression model, and the results of this analysis are displayed as a colorcoded map. Plaque components are usually categorized into 4 tissue types: fibrous, fibro-fatty, calcified and calcified necrotic $[13,14]$. The diagnostic accuracy of VH has been validated against histology, thus enabling the differentiation of the various components of the plaque under study.

The Providing Regional Observations to Study Predictors of Events in the Coronary Tree (PROSPECT) trial was a natural-history study using multimodality imaging of the entire coronary tree that showed that approximately $20 \%$ of patients with ACS treated with stents and optimal medical therapy developed major adverse cardiac events within 3 years, and 12\% of these patients developed events from nonculprit lesions [15], the same rate as in culprit lesions.

\section{Integrated Backscatter IVUS}

IB-IVUS was developed in order to overcome the limitations of grayscale IVUS. The IB values of the different tissue components can be used to generate a color-coded IB-IVUS image. Both ex vivo [16, 17] and in vivo [18] studies have validated the accuracy of this approach. An autopsy-based study of 42 coronary specimens showed the sensitivity of IB-IVUS for calcification, fibrous and lipid-rich plaque to be 100,94 and $84 \%$, respectively, which compares favorably with optical coherence tomography (OCT; 100, 98 and 95\%, respectively) and conventional IVUS (100, 93 and 67\%, respectively) [19]. When compared with VH-IVUS, IB-IVUS provided higher diagnostic agreement with histological assessment [20].

\section{Elastography and Palpography}

Elastography and palpography are methods utilizing IVUS-derived data that assess the local strain of the vessel wall and plaque. A color-coded map is obtained that shows areas with high mechanical strain. High-strain regions denoting vulnerable plaques detected by these two methods have been identified in experimental models and in humans [21]. The recent publication of the palpography arm of the PROSPECT trial has shown that the predictive value of palpography for detection of future events is fairly limited [22]. 


\section{Coronary Angioscopy}

Coronary angioscopy allows the visualization of the inner surface of the vessel and concomitantly the atheromatic plaque. The intensity of the yellow color detected (slight yellow, yellow, intensive yellow) is used for plaque characterization [23], and intense yellow color of the plaque has been linked with ACS. However, coronary angioscopy is unable to provide details regarding the interior of the plaque, rendering its use futile.

\section{Optical Coherence Tomography}

OCT is a light-based imaging modality able to visualize the majority of the morphological characteristics of the vulnerable plaque, including the type of plaque, the lipid core size, the exact thickness of the fibrous plaque $[24,25]$, neovascularization and plaque infiltration by macrophages [26], and can also provide precise morphological assessment of the ruptured plaque and not only detect the presence and extent of thrombosis but characterize the type of thrombus as well [27-29]. The combined use of OCT and VH-IVUS has shown encouraging results [30], and further studies with the combined usage of these modalities are warranted.

Furthermore, OCT has provided useful insights into the localization of high-risk plaques. An in vivo OCT study has shown that $76 \%$ of thin-cap fibroatheromas were found on the first $30 \mathrm{~mm}$ from the left anterior descending artery orifice [31]. These results have been confirmed by other studies, where culprit lesions of ACS patients located in the proximal segments of the left anterior descending artery have a thin fibrous cap and increased incidence of plaque rupture compared to distal culprit lesions [32].

Limitations of OCT include limited penetration that allows for imaging of the superficial $1.5-2 \mathrm{~cm}$ of the plaque surface but does not allow the precise assessment of plaque burden and the remodeling index. Nevertheless, the majority of the 'vulnerable' morphological characteristics are located near the surface of the plaque, while the introduction of second-generation OCT systems with high-speed image acquisition in clinical practice helps overcome limitations of first-generation systems that required prolonged displacement of the blood from the studied artery.

\section{Near-Infrared Spectroscopy}

Near-infrared spectroscopy (NIRS) evaluates the spectrum of absorption of near-infrared light with differing wavelengths by different tissue components in order to identify the chemical composition of the substance. A color-coded map is formed where yellow corresponds to high probability and red corresponds to low probability of lipid-core plaque. Recently, in an autopsy study, NIRS was used successfully to identify lipid-core plaques and correlated well with histology [33]. A combined NIRSIVUS catheter has also been used that enables both plaque architecture and composition identification, thus enabling culprit and nonculprit lesion identification and stent length selection [34]. Nonetheless, this combined catheter has yet to be tested in a larger cohort, and further results are awaited.

\section{Intravascular Thermography}

Ex vivo specimens of atherosclerotic plaques have been shown to be associated with thermal heterogeneity, as a result of heat production by macrophages, and thus thermal heterogeneity can be used as a surrogate marker for detection of heavily inflamed plaques. In the first-in-man study of an intravascular catheter for the assessment of thermal heterogeneity in atherosclerotic plaques, culprit plaques of patients with ACS were found to have higher temperature differences compared to those in patients with stable angina [35]. Furthermore, a prospective study in 86 patients undergoing a percutaneous coronary intervention showed that increased local temperature in atherosclerotic plaques is a strong predictor of unfavorable adverse events [36]. Another study using thermography and IVUS has shown that the site with the highest temperature is distal to the angiographically most stenotic site [37], accurately localizing the culprit lesion. Furthermore, combined plaque assessment by IVUS and thermography has shown that plaques with expansive remodeling and ruptured plaques are associated with increased local inflammatory activation, as demonstrated by an increased temperature difference [38]. The use of thermography for vulnerable plaque detection is limited due to the cooling effect of blood flow that causes underestimation of temperature differences and due to the need for the tip of the catheter to be in contact with the vessel wall being studied [39], which could lead to vessel damage.

\section{Noninvasive Imaging}

The development of noninvasive modalities for the detection of the vulnerable plaque has been the subject of intensive research interest. However, despite technological advancements, noninvasive imaging modalities still have poor sensitivity, specificity and resolution and so they cannot detect the features of the vulnerable plaque. 
Multidetector Computed Tomography

The accuracy of multidetector computed tomography has increased, as has the ability to imagine the vessel wall [40]. The multidetector computed tomography criteria for plaque vulnerability have been validated against $\mathrm{VH}$ and OCT in ACS patients [41-43], as well as in plaques which were not heavily calcified [42].

\section{Magnetic Resonance Imaging}

MRI is usually applied for large and static arteries, since the continuous motion of the coronary arteries remains an obstacle for imaging them. Furthermore, the poor reproducibility of MRI is the main restriction for vulnerable plaque detection [44], whereas newer studies have showed that high-intensity plaques lead to ischemic events [45].

\section{Nuclear Imaging}

Nuclear imaging modalities, such as single-photon emission computed tomography and positron emission tomography, have also been extensively studied. Positron emission tomography has a better resolution and less diagnostic uncertainty, so it has been used in most of the studies on nuclear imaging of atherosclerosis [46]. ${ }^{18} \mathrm{~F}$ labeled fluorodeoxyglucose is a tracer currently being used for detecting metabolically active cells. In humans with carotid atherosclerosis [47], areas of high ${ }^{18} \mathrm{~F}$-labeled fluorodeoxyglucose uptake have been shown to colocalize with areas of macrophage accumulation, irrespective of plaque size or luminal narrowing.

\section{Contrast-Enhanced Ultrasonography}

Contrast-enhanced ultrasonography has been used for imaging the inflammatory response by detecting vascular cell adhesion molecule- 1 in the aorta [48], which allows for the monitoring of the various atherosclerosis stages.

\section{Microwave Radiometry}

Microwave radiometry (MR) is a novel method that measures natural electromagnetic radiation from a patient's internal tissues at microwave frequencies. MR has been used previously to detect temperature changes in breast cancer patients. Recently, MR was applied to an experimental hypercholesterolemic model, and thermal heterogeneity was measured with both MR and intravascular thermography. The results showed good correlation between the two methods, as well as with the histological findings [49].
After experimental demonstration, MR was tested in vivo in patients with carotid artery disease who were scheduled for endarterectomy. Besides MR measurement, these patients also underwent carotid echocardiography and histological and immunohistochemical studies following endarterectomy. The results were encouraging, as they revealed a positive correlation of the MR temperature measurements with the echocardiographic characteristics of the vulnerable plaques [50].

\section{Future Perspectives}

Currently, there is no imaging method that can properly assess all the aspects of plaque vulnerability. Moreover, each modality has its own advantages and disadvantages. An imaging modality that can be used for vulnerable plaque detection needs to be safe, efficient and ideally cost-effective. Due to their invasiveness and high cost, intravascular methods cannot be used as a screening tool for the general population. Moreover, their use in high-risk individuals cannot be justified because (1) besides the PROSPECT trial there are currently no other large-scale natural-history studies providing proof of a potential improvement in patient-related outcomes by using intravascular imaging for the detection of high-risk plaque, (2) the high-risk morphological characteristics that are more crucial for the determination of plaque vulnerability and consequently the ideal modality for vulnerable plaque detection have not been identified and (3) the dynamic changes in plaque morphology, principally affected by local rheological conditions, make morphological assessment alone insufficient for the determination of vulnerable plaque.

Consequently, the development of a modality able to detect vulnerable plaques will have to focus not only on the assessment of morphology but also on the functional assessment of the plaque. A combination of morphological assessment by OCT with shear stress assessment could perhaps be applied for vulnerable plaque characterization in very high-risk individuals already treated with intensive medical therapy. The development of new therapeutic tools dedicated to the passivation of vulnerable plaques could potentially fulfill the expectation of local treatment of these plaques and allow prevention of future events.

Furthermore, the development of noninvasive methods that will be able to provide imaging biomarkers of plaque vulnerability could improve risk stratification on a population-level basis and identify individuals in need of intensive treatment. 


\section{Conclusion}

Invasive imaging is still the cornerstone for imaging and detecting the vulnerable plaque, while noninvasive imaging modalities have an increasingly important role in detecting the vulnerable plaque or conditions associated with coronary heart disease and can be of great value and assistance in addition to invasive modalities.

\section{References}

1 Lloyd-Jones D, Adams RJ, Brown TM, Carnethon M, Dai S, De Simone G, Ferguson TB, Ford E, Furie K, Gillespie C, Go A, Greenlund K, Haase N, Hailpern S, Ho PM, Howard V, Kissela B, Kittner S, Lackland D, Lisabeth L, Marelli A, McDermott MM, Meigs J, Mozaffarian D, Mussolino M, Nichol G, Roger VL, Rosamond W, Sacco R, Sorlie P, Roger VL, Thom T, Wasserthiel-Smoller S, Wong ND, Wylie-Rosett J: Heart disease and stroke statistics - 2010 update: a report from the American Heart Association. Circulation 2010;121:e46-e215.

2 Allender S, Scarborough P, Peto V, Rayner M, Leal J, Luengo-Fernandez R, Gray A: European Cardiovascular Disease Statistics 2008. Brussels, European Heart Network, 2008.

-3 Anderson KM, Wilson PW, Odell PM, Kannel WB: An updated coronary risk profile. A statement for health professionals. Circulation 1991;83:356-362.

$\checkmark 4$ Conroy RM, Pyorala K, Fitzgerald AP, Sans S, Menotti A, De Backer G, De Bacquer D, Ducimetiere P, Jousilahti P, Keil U, Njolstad I, Oganov RG, Thomsen T, Tunstall-Pedoe $\mathrm{H}$, Tverdal A, Wedel H, Whincup P, Wilhelmsen L, Graham IM: Estimation of tenyear risk of fatal cardiovascular disease in Europe: the SCORE project. Eur Heart J 2003;24:987-1003.

5 Zarich S, Luciano C, Hulford J, Abdullah A: Prevalence of metabolic syndrome in young patients with acute MI: does the Framingham Risk Score underestimate cardiovascular risk in this population? Diab Vasc Dis Res 2006;3:103-107.

-6 Kalantzi K, Korantzopoulos P, Tzimas P, Katsouras CS, Goudevenos JA, Milionis HJ: The relative value of metabolic syndrome and cardiovascular risk score estimates in premature acute coronary syndromes. Am Heart J 2008;155:534-540.

-7 Schaar JA, Muller JE, Falk E, Virmani R, Fuster V, Serruys PW, Colombo A, Stefanadis C, Ward Casscells S, Moreno PR, Maseri A, van der Steen AF: Terminology for highrisk and vulnerable coronary artery plaques. Report of a meeting on the vulnerable plaque, June 17 and 18, 2003, Santorini, Greece. Eur Heart J 2004;25:1077-1082.

$\checkmark 8$ Falk E, Shah PK, Fuster V: Coronary plaque disruption. Circulation 1995;92:657-671.

-9 Ferrante G, Nakano M, Prati F, Niccoli G, Mallus MT, Ramazzotti V, Montone RA, Kolodgie FD, Virmani R, Crea F: High levels of systemic myeloperoxidase are associated with coronary plaque erosion in patients with acute coronary syndromes: a clinicopathological study. Circulation 2010;122: 2505-2513.

10 Karanasos A, Ligthart J, Witberg K, Regar E: Calcified nodules: an underrated mechanism of coronary thrombosis? JACC Cardiovasc Imaging 2012;5:1071-1072.

11 Virmani R, Kolodgie FD, Burke AP, Farb A, Schwartz SM: Lessons from sudden coronary death: a comprehensive morphological classification scheme for atherosclerotic lesions. Arterioscler Thromb Vasc Biol 2000; 20:1262-1275.

12 Mintz GS, Nissen SE, Anderson WD, Bailey SR, Erbel R, Fitzgerald PJ, Pinto FJ, Rosenfield K, Siegel RJ, Tuzcu EM, Yock PG: American College of Cardiology Clinical Expert Consensus Document on Standards for Acquisition, Measurement and Reporting of Intravascular Ultrasound Studies (IVUS). A report of the American College of Cardiology Task Force on Clinical Expert Consensus Documents. J Am Coll Cardiol 2001;37: 1478-1492.

13 Konig A, Margolis MP, Virmani R, Holmes $\mathrm{D}$, Klauss V: Technology insight: in vivo coronary plaque classification by intravascular ultrasonography radiofrequency analysis. Nat Clin Pract Cardiovasc Med 2008;5:219229.

14 Mehta SK, McCrary JR, Frutkin AD, Dolla WJ, Marso SP: Intravascular ultrasound radiofrequency analysis of coronary atherosclerosis: an emerging technology for the assessment of vulnerable plaque. Eur Heart J 2007;28:1283-1288.

15 Stone GW, Maehara A, Lansky AJ, de Bruyne B, Cristea E, Mintz GS, Mehran R, McPherson J, Farhat N, Marso SP, Parise H, Templin B, White R, Zhang Z, Serruys PW: A prospective natural-history study of coronary atherosclerosis. N Engl J Med 2011;364:226-235.

6 Kawasaki M, Takatsu H, Noda T, Sano K, Ito Y, Hayakawa K, Tsuchiya K, Arai M, Nishigaki K, Takemura G, Minatoguchi S, Fujiwara T, Fujiwara $\mathrm{H}$ : In vivo quantitative tissue characterization of human coronary arterial plaques by use of integrated backscatter intravascular ultrasound and comparison with angioscopic findings. Circulation 2002; 105:2487-2492.

17 Moore MP, Spencer T, Salter DM, Kearney PP, Shaw TR, Starkey IR, Fitzgerald PJ, Erbel R, Lange A, McDicken NW, Sutherland GR, Fox KA: Characterisation of coronary atherosclerotic morphology by spectral analysis of radiofrequency signal: in vitro intravascu- lar ultrasound study with histological and radiological validation. Heart 1998;79:459467.

18 Sano K, Kawasaki M, Ishihara Y, Okubo M, Tsuchiya K, Nishigaki K, Zhou X, Minatoguchi S, Fujita H, Fujiwara H: Assessment of vulnerable plaques causing acute coronary syndrome using integrated backscatter intravascular ultrasound. J Am Coll Cardiol 2006;47:734-741.

19 Kawasaki M, Bouma BE, Bressner J, Houser SL, Nadkarni SK, MacNeill BD, Jang IK, Fujiwara H, Tearney GJ: Diagnostic accuracy of optical coherence tomography and integrated backscatter intravascular ultrasound images for tissue characterization of human coronary plaques. J Am Coll Cardiol 2006; 48:81-88

20 Okubo M, Kawasaki M, Ishihara Y, Takeyama U, Yasuda S, Kubota T, Tanaka S, Yamaki T, Ojio S, Nishigaki K, Takemura G, Saio M, Takami T, Fujiwara H, Minatoguchi S: Tissue characterization of coronary plaques: comparison of integrated backscatter intravascular ultrasound with virtual histology intravascular ultrasound. Circ J 2008;72: 1631-1639.

21 Schaar JA, van der Steen AF, Mastik F, Baldewsing RA, Serruys PW: Intravascular palpography for vulnerable plaque assessment. J Am Coll Cardiol 2006;47:C86-C91.

- 22 Brugaletta S, Garcia-Garcia HM, Serruys PW, Maehara A, Farooq V, Mintz GS, de Bruyne B, Marso SP, Verheye S, Dudek D, Hamm CW, Farhat N, Schiele F, McPherson J, Lerman A, Moreno PR, Wennerblom B, Fahy M, Templin B, Morel MA, van Es GA, Stone GW: Relationship between palpography and virtual histology in patients with acute coronary syndromes. JACC Cardiovasc Imaging 2012;5:S19-S27.

23 Masumura Y, Ueda Y, Matsuo K, Akazawa Y, Nishio M, Hirata A, Kashiwase K, Nemoto T, Kashiyama T, Wada M, Muller JE, Kodama $\mathrm{K}$ : Frequency and location of yellow and disrupted coronary plaques in patients as detected by angioscopy. Circ J 2011;75:603-612.

24 Toutouzas K, Karanasos A, Tsiamis E, Riga M, Drakopoulou M, Synetos A, Papanikolaou A, Tsioufis C, Androulakis A, Stefanadi E, Tousoulis D, Stefanadis C: New insights by optical coherence tomography into the differences and similarities of culprit ruptured plaque morphology in non-ST-elevation myocardial infarction and ST-elevation myocardial infarction. Am Heart J 2011;161: 1192-1199. 
25 Toutouzas K, Tsiamis E, Karanasos A, Drakopoulou M, Synetos A, Tsioufis C, Tousoulis D, Davlouros P, Alexopoulos D, Bouki K, Apostolou T, Stefanadis C: Morphological characteristics of culprit atheromatic plaque are associated with coronary flow after thrombolytic therapy: new implications of optical coherence tomography from a multicenter study. JACC Cardiovasc Interv 2010; 3:507-514.

$>26$ Raffel OC, Tearney GJ, Gauthier DD, Halpern EF, Bouma BE, Jang IK: Relationship between a systemic inflammatory marker, plaque inflammation, and plaque characteristics determined by intravascular optical coherence tomography. Arterioscler Thromb Vasc Biol 2007;27:1820-1827.

-27 Toutouzas K, Karanasos A, Stefanadis C: Multiple plaque morphologies assessed by optical coherence tomography in a patient with acute coronary syndrome. Heart 2010; 96:1335-1336.

-28 Prati F, Regar E, Mintz GS, Arbustini E, Di Mario C, Jang IK, Akasaka T, Costa M, Guagliumi G, Grube E, Ozaki Y, Pinto F, Serruys PW: Expert review document on methodology, terminology, and clinical applications of optical coherence tomography: physical principles, methodology of image acquisition, and clinical application for assessment of coronary arteries and atherosclerosis. Eur Heart J 2010;31:401-415.

-29 Toutouzas K, Karanasos A, Stathogiannis K, Synetos A, Tsiamis E, Papadopoulos D, Stefanadis C: A honeycomb-like structure in the left anterior descending coronary artery: demonstration of recanalized thrombus by optical coherence tomography. JACC Cardiovasc Interv 2012;5:688-689.

-30 Sawada T, Shite J, Garcia-Garcia HM, Shinke $\mathrm{T}$, Watanabe $\mathrm{S}$, Otake $\mathrm{H}$, Matsumoto $\mathrm{D}$, Tanino Y, Ogasawara D, Kawamori H, Kato $\mathrm{H}$, Miyoshi N, Yokoyama M, Serruys PW, Hirata K: Feasibility of combined use of intravascular ultrasound radiofrequency data analysis and optical coherence tomography for detecting thin-cap fibroatheroma. Eur Heart J 2008;29:1136-1146.

-31 Fujii K, Kawasaki D, Masutani M, Okumura T, Akagami T, Sakoda T, Tsujino T, Ohyanagi $\mathrm{M}$, Masuyama T: OCT assessment of thincap fibroatheroma distribution in native coronary arteries. JACC Cardiovasc Imaging 2010;3:168-175.

>32 Toutouzas K, Karanasos A, Riga M, Tsiamis E, Synetos A, Michelongona A, Papanikolaou A, Triantafylloy G, Tsioufis C, Stefanadis C: Optical coherence tomography assessment of the spatial distribution of culprit ruptured plaques and thin-cap fibroatheromas in acute coronary syndrome. EuroIntervention 2012;8:477-485.
33 Gardner CM, Tan H, Hull EL, Lisauskas JB, Sum ST, Meese TM, Jiang C, Madden SP, Caplan JD, Burke AP, Virmani R, Goldstein J, Muller JE: Detection of lipid core coronary plaques in autopsy specimens with a novel catheter-based near-infrared spectroscopy system. JACC Cardiovasc Imaging 2008; 1: 638-648.

34 Madder RD, Steinberg DH, Anderson RD: Multimodality direct coronary imaging with combined near-infrared spectroscopy and intravascular ultrasound: initial US experience. Catheter Cardiovasc Interv 2011, E-pub ahead of print.

35 Stefanadis C, Diamantopoulos L, Vlachopoulos C, Tsiamis E, Dernellis J, Toutouzas K, Stefanadi E, Toutouzas P: Thermal heterogeneity within human atherosclerotic coronary arteries detected in vivo: a new method of detection by application of a special thermography catheter. Circulation 1999;99:1965-1971.

36 Stefanadis C, Toutouzas K, Tsiamis E, Stratos C, Vavuranakis M, Kallikazaros I, Panagiotakos D, Toutouzas P: Increased local temperature in human coronary atherosclerotic plaques: an independent predictor of clinical outcome in patients undergoing a percutaneous coronary intervention. J Am Coll Cardiol 2001;37:1277-1283.

37 Takumi T, Lee S, Hamasaki S, Toyonaga K, Kanda D, Kusumoto K, Toda H, Takenaka T, Miyata M, Anan R, Otsuji Y, Tei C: Limitation of angiography to identify the culprit plaque in acute myocardial infarction with coronary total occlusion utility of coronary plaque temperature measurement to identify the culprit plaque. J Am Coll Cardiol 2007; 50:2197-2203.

38 Toutouzas K, Synetos A, Stefanadi E, Vaina S, Markou V, Vavuranakis M, Tsiamis E, Tousoulis D, Stefanadis C: Correlation between morphologic characteristics and local temperature differences in culprit lesions of patients with symptomatic coronary artery disease. J Am Coll Cardiol 2007;49:22642271.

39 Stefanadis C, Toutouzas K, Tsiamis E, Mitropoulos I, Tsioufis C, Kallikazaros I, Pitsavos C, Toutouzas P: Thermal heterogeneity in stable human coronary atherosclerotic plaques is underestimated in vivo: the 'cooling effect' of blood flow. J Am Coll Cardiol 2003;41:403-408.

40 Goldstein JA: Coronary plaque characterization by computed tomographic angiography: present promise and future hope. JACC Cardiovasc Imaging 2009;2:161-163.

41 Kubo T, Matsuo Y, Ino Y, Kitabata H, Tanimoto T, Ishibashi K, Okumoto Y, Nakamura K, Komukai K, Takarada S, Tanaka A, Imanishi T, Akagi H, Akasaka T: Diagnostic accuracy of CT angiography to assess coronary stent thrombosis as determined by intravascular OCT. JACC Cardiovasc Imaging 2011; 4:1040-1043.
42 van Velzen JE, de Graaf FR, Jukema JW, de Grooth GJ, Pundziute G, Kroft LJ, de Roos A, Reiber JH, Bax JJ, Schalij MJ, Schuijf JD, van der Wall EE: Comparison of the relation between the calcium score and plaque characteristics in patients with acute coronary syndrome versus patients with stable coronary artery disease, assessed by computed tomography angiography and virtual histology intravascular ultrasound. Am J Cardiol 2011; 108:658-664.

43 Pundziute G, Schuijf JD, Jukema JW, Decramer I, Sarno G, Vanhoenacker PK, Boersma E, Reiber JH, Schalij MJ, Wijns W, Bax JJ: Evaluation of plaque characteristics in acute coronary syndromes: non-invasive assessment with multi-slice computed tomography and invasive evaluation with intravascular ultrasound radiofrequency data analysis. Eur Heart J 2008;29:2373-2381.

-44 Kwee RM, van Engelshoven JM, Mess WH, ter Berg JW, Schreuder FH, Franke CL, Korten AG, Meems BJ, van Oostenbrugge RJ, Wildberger JE, Kooi ME: Reproducibility of fibrous cap status assessment of carotid artery plaques by contrast-enhanced MRI. Stroke 2009;40:3017-3021.

-45 Noguchi T, Yamada N, Higashi M, Goto Y, Naito H: High-intensity signals in carotid plaques on T1-weighted magnetic resonance imaging predict coronary events in patients with coronary artery disease. J Am Coll Cardiol 2011;58:416-422.

46 Vancraeynest D, Pasquet A, Roelants V, Gerber BL, Vanoverschelde JL: Imaging the vulnerable plaque. J Am Coll Cardiol 2011;57: 1961-1979.

47 Tahara N, Kai H, Nakaura H, Mizoguchi M, Ishibashi M, Kaida H, Baba K, Hayabuchi N, Imaizumi T: The prevalence of inflammation in carotid atherosclerosis: analysis with fluorodeoxyglucose-positron emission tomography. Eur Heart J 2007;28:2243-2248.

48 Kaufmann BA, Sanders JM, Davis C, Xie A, Aldred P, Sarembock IJ, Lindner JR: Molecular imaging of inflammation in atherosclerosis with targeted ultrasound detection of vascular cell adhesion molecule-1. Circulation 2007; 116:276-284.

-49 Toutouzas K, Grassos H, Synetos A, Drakopoulou M, Tsiamis E, Moldovan C, Agrogiannis G, Patsouris E, Siores E, Stefanadis C: A new non-invasive method for detection of local inflammation in atherosclerotic plaques: experimental application of microwave radiometry. Atherosclerosis 2011;215: 82-89.

50 Toutouzas K, Grassos C, Drakopoulou M, Synetos A, Tsiamis E, Aggeli C, Stathogiannis K, Klettas D, Kavantzas N, Agrogiannis G, Patsouris E, Klonaris C, Liasis N, Tousoulis D, Siores E, Stefanadis C: First in vivo application of microwave radiometry in human carotids: a new noninvasive method for detection of local inflammatory activation. J Am Coll Cardiol 2012;59:1645-1653. 